\title{
Estimation of Carbon Sequestration of Selected Tree Species in Intanki National Park, Nagaland, India
}

\author{
Anguno Tase ${ }^{*}$, Amit Larkin and Hemant Kumar \\ College of Forestry, Sam Higginbottom University of Agriculture Technology \& Sciences, \\ Allahabad-U.P-211007, India \\ *Corresponding author
}

\section{A B S T R A C T}

\section{Keywords}

Above ground biomass, Below ground biomass, Carbon sequestration,

Moisture content, Fixed carbon, Climate change

Article Info

Accepted:

10 August 2018

Available Online:

10 September 2018
The study was carried out to investigate the above ground biomass, below ground biomass and estimate the total carbon sequestration of the selected tree species found in Intanki National Park, Nagaland viz., Tetrameles nudiflora, Cyclostemum assamicus, Mansonia dipikae, Dillenia indica, Bischofia javanica, Polyathia cerasoides and Amoora wallichii by non-destructive method. The estimation of the biomass was performed by measuring the tree height and diameter with the help of Ravi altimeter and measuring tape respectively. Total above ground biomass was recorded highest for the Bischofia javanica ( 7.570 tons tree $\left.{ }^{-1}\right)$ while the maximum below ground biomass ( 1.133 ton tre $e^{-1}$ ) was observed for Mansonia dipikae. The maximum wood moisture content (61\%) was recorded for Tetrameles nudiflora. Maximum fixed carbon $(62.7 \%)$ was recorded in Cyclostemum assamicus while the minimum (38.4\%) was recorded for Tetrameles nudiflora. It was also observed that the amount of carbon sequestration was highest $(2.977$ $\mathrm{t} \mathrm{C}$ tre $\left.^{-1}\right)$ in Bischofia javanica and the minimum $\left(0.066 \mathrm{t} \mathrm{C}\right.$ tree $\left.{ }^{-1}\right)$ was recorded for Mansonia dipikae. The trees which were examined are important multipurpose tree species grown in Intanki National Park and are significant components of Agro forestry and plantation forestry in the study region.

\section{Introduction}

The threat of climate change is now overwhelming the dialogue on forest policy. Forests, like other ecosystems, will be affected by temperature increase. But the dimension that is receiving much more attention is their role as a store for carbon. Forests hold more carbon than the atmosphere, and the interchange of carbon between the two is a major element in the climate change, and reducing this is seen as a low-cost way of mitigating the threat of climate change.
Tropical forests play an important role in the global carbon cycle based both in terms of regulating the carbon flux between the biosphere and the atmosphere, and in terms of the amount of carbon stored. Tropical forests harbouring rich biodiversity are responding in several ways to global climate change leading to shifts in species composition and overall increase in turnover (Phillips and Gentry, 1994). Tropical forests clearly dominate the role of forests in the global carbon cycle based both on $\mathrm{C}$ flux, and the volume of carbon stored. Deforestation and forest degradation in 
the tropics currently account for about $20 \%$ of the GHG emissions and constitute the majority of emissions from developing countries (IPCC, 2007; Gullison et al., 2007). Reduced Emissions recognizing the importance of tropical forests and the value of developing countries participation in the global REDD is an instrument to maintain carbon pools, support sustainable development and mechanism to reward countries with carbon credits for preserving their forest cover. Species play a potentially important role enhancing ecosystem capacity to recover and adapt to the impacts of climate change. Substantial amounts of carbon can be sequestered through forestry, compared to the net volume of carbon released into the atmosphere. Tropical forests are one of the riches and complex terrestrial ecosystems supporting a variety of life forms and have a tremendous ability for self-sustain. Due to increasing biotic, anthropogenic interference, grazing and other illegal activities these forests are losing their ability (Swamy et al., 2010).

It is a well-known fact now that forests are important component of global carbon (C) cycle. Forests are part of a wider ecosystem and deliver services that are far more than forest even from the perspective of climate change. (Dixon et al., (1994) estimated that approximately 1146 pentagrams of carbon are stored in the world's forested ecosystems. Forest account for more than $75 \%$ of the carbon stored in terrestrial ecosystems and approximately $40 \%$ of the carbon exchange between the atmosphere and the terrestrial biosphere each year (Schlesinger, 1997). Indian forests are known to be one of the richest in terms of vegetation types and species diversity. Forest plays a major role in the global carbonic cycle by capturing carbon (C) from the atmosphere through photosynthesis, converting it to forest biomass and releasing it into the atmosphere through plant respiration and decomposition. Plants and especially forests are of particular importance as they are major regulators of global climate and are keystone of the carbon cycle. Forest already serves as a substantial warehouse for carbon. Forest growth naturally stores, or "sequesters" carbon, and the carbon remains in the wood after it is processed into a product. Climate change escalates the already existing vulnerabilities of Nagaland and could manifest disastrously if not addressed adequately. Chaturvedi (1994) estimated that in Indian forests, one tonne of carbon could be sequestered by 2.2 tonnes of wood. Studies have established that carbon sequestration by trees could provide relatively net emission reductions (Callaway and McCarl, 1996, Stavins, 1999).

\section{Materials and Methods}

The experiment was conducted in Intanki National Park, Nagaland. Intanki is located in Peren District of Nagaland and spreads over an area of $202 \mathrm{~km}^{2}$. It's altitude varies from $200 \mathrm{~m}$ to $682 \mathrm{~m} \mathrm{(msl)}$ at $93^{\circ} 15^{\prime}$ to $25^{\circ} 18^{\prime}$ to $25^{\circ} 43^{\prime} \mathrm{N}$ latitude and $93^{\circ} 43^{\prime}$ longitude. The temperature generally ranges from less than 0 degree Celsius to 35 degree C. In summer, maximum and minimum temperature is 31 degree $\mathrm{C}$ to 16 degree $\mathrm{C}$ respectively. Forest of this National park is of Tropical moist deciduous and Tropical semi-evergreen type. Three trees of each species were selected and three samples of $10 \times 3 \times 2 \mathrm{~cm}$ were collected from each tree. The species selected Tetrameles nudiflora, Cyclostemum assamicus, Mansonia dipikae, Dillenia indica, Bischofia javanica, Polyathia cerasoides, Amoorawalichii.

\section{Biophysical measurements}

The height and diameter at breast height $(\mathrm{DBH})$ are the two main biophysical measurements which were measured for each 
tree sample. The tree height was determined with the help of RAVI ALTIMETER in meters. Diameter at breast height was measured in meters using measuring tape.

Above-ground biomass includes all living biomass above the soil. The above-ground biomass (AGB) has been calculated by multiplying volume with specific gravity.

The volume was calculated based on diameter and height.

Specific gravity was calculated by the ratio of oven dry weight and green volume of the pieces of wood samples.

Aboveground biomass ( $\mathrm{t} \mathrm{C}$ tree $\left.\mathrm{e}^{-1}\right)=$ Volume of tree $\left(\mathrm{m}^{3}\right)$ x specific gravity $\left(\mathrm{g} \mathrm{cm}^{3}\right)$

The Below Ground Biomass (BGB) includes all biomass. The belowground biomass (BGB) accounts for about $15 \%$ of the total tree biomass.

Belowground biomass $\left(\mathrm{t}\right.$ tree $\left.^{-1}\right)=$ AGB $\mathrm{X}$ $(15 / 100)$

Fixed carbon mainly contributes to carbon storage.

It was calculated as:

Fixed carbon $(\%)=100-$ Ash content Moisture content (Ganeshaiah et al., 2003).
Total carbon sequestration was estimated as the product of total above ground biomass and fixed carbon.

Total carbon sequestration $\left(\mathrm{t} \mathrm{C}\right.$ tree $\left.{ }^{-1}\right)=$ Total Biomass x Fixed carbon (\%). (Jana et al., 2009).

\section{Results and Discussion}

\section{Biomass estimation}

The biomass of the selected tree species is shown in Table 1 and Figure 1. The maximum above ground biomass $7.570 \mathrm{tC}$ tree $^{-1}$ was found for Bischofia javanica, the minimum $1.856 \mathrm{tC}^{\text {tree }^{-1}}$ was found for Polyathia cerasoides. The maximum below ground biomass 1.133 tC $\operatorname{tree}^{-1}$ was found for Mansonia dipikaefollowed by Bischofia javanica $0.954 \mathrm{tC}$ tree ${ }^{-1}$, the minimum was found for Polyathia cerasoides $0.278 \mathrm{tC}$ tree $^{-1}$. And the maximum total biomass was found for Mansonia dipikae with $8.687 \mathrm{tC}$ tree $^{-1}$ with the minimum observed in Polyathiacerasoides $2.134 \mathrm{tC}$ tree $^{-1}$.

\section{Fixed carbon estimation}

From figure 2 it has been observed that the highest fixed carbon was recorded $62.7 \%$ was recorded for Cyclostemum assamicus which was statistically at par with Amoorawalichi $59.3 \%$. The minimum fixed carbon $38 \%$ was obtained for Tetrameles nudiflora.

Table.1 Aboveground biomass (AGB), belowground biomass (BGB) and Total biomass (TB) of the selected tree species

\begin{tabular}{|c|c|c|c|c|}
\hline $\mathbf{S . N}$ & Species & AGB $\left(t\right.$ tree $\left.^{-1}\right)$ & BGB $\left(t\right.$ tree $^{-1)}$ & TB $\left(\right.$ tree $\left.^{-1}\right)$ \\
\hline 1 & Tetrameles nudiflora & 6.509 & 0.929 & 7.438 \\
\hline 2 & Cyclostemum assamicus & 2.010 & 0.307 & 2.317 \\
\hline 3 & Mansonia dipikae & 7.554 & 1.133 & 8.687 \\
\hline 4 & Dillenia indica & 2.735 & 0.374 & 3.109 \\
\hline 5 & Bischofia javanica & 7.570 & 0.954 & 8.524 \\
\hline 6 & Polythia cerasoides & 1.856 & 0.278 & 2.134 \\
\hline 7 & Amoora wallichii & 1.933 & 0.302 & 2.235 \\
\hline
\end{tabular}


Fig.1 Location of the study area (Intanki National Park, Nagaland)

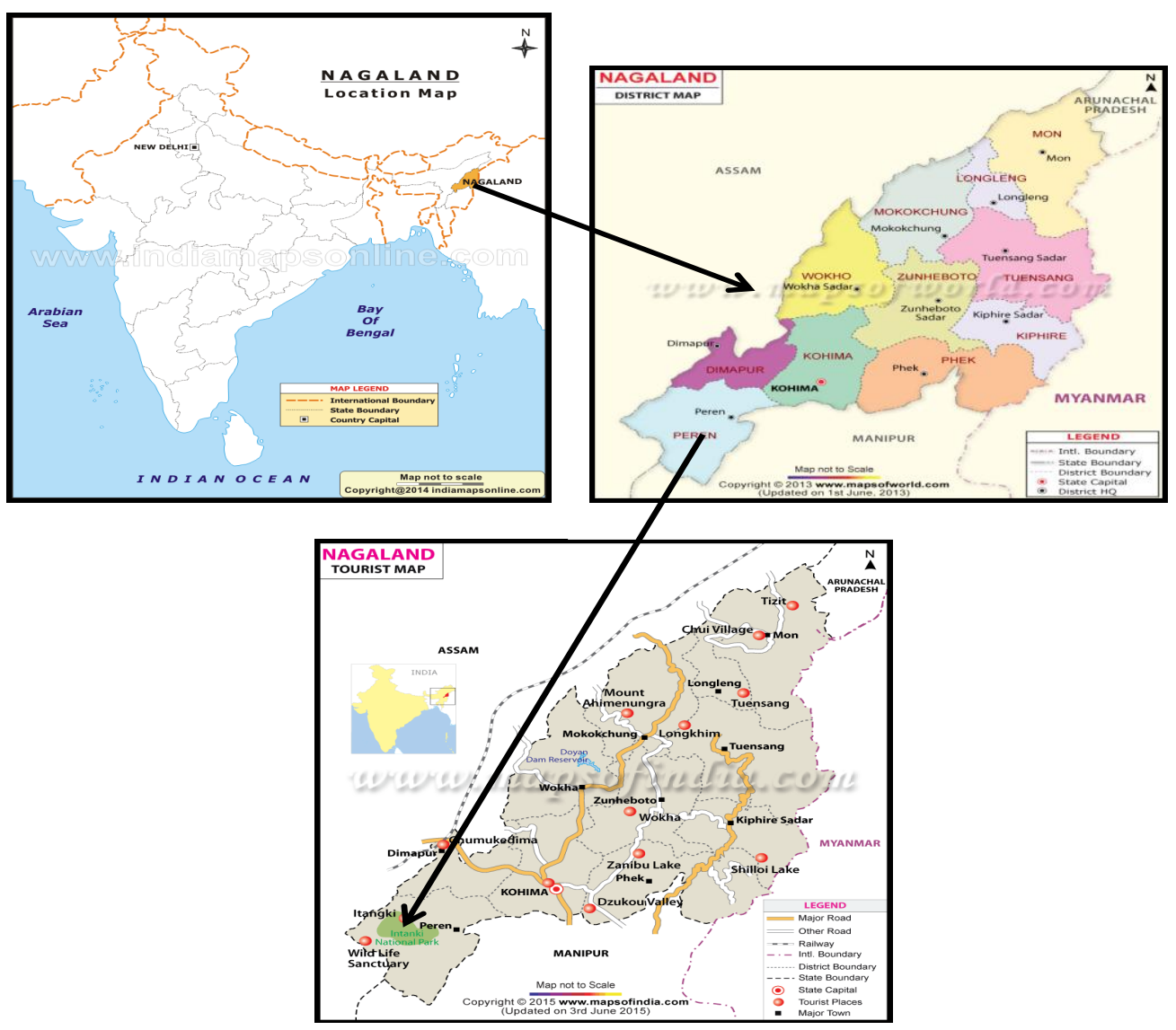

Fig.2 Total biomass variation in the different tree species

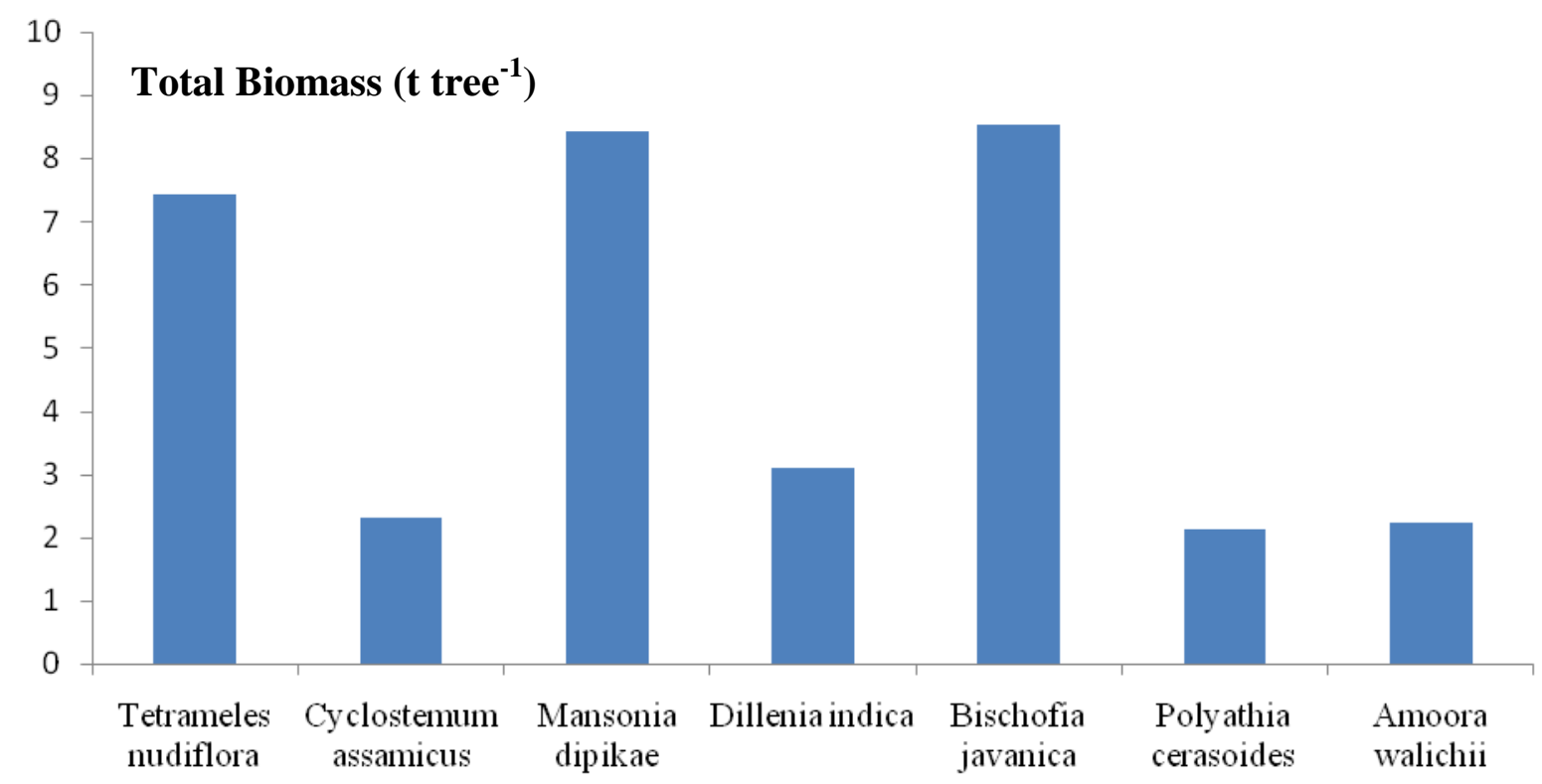


Fig.3 Fixed carbon of the different tree species selected

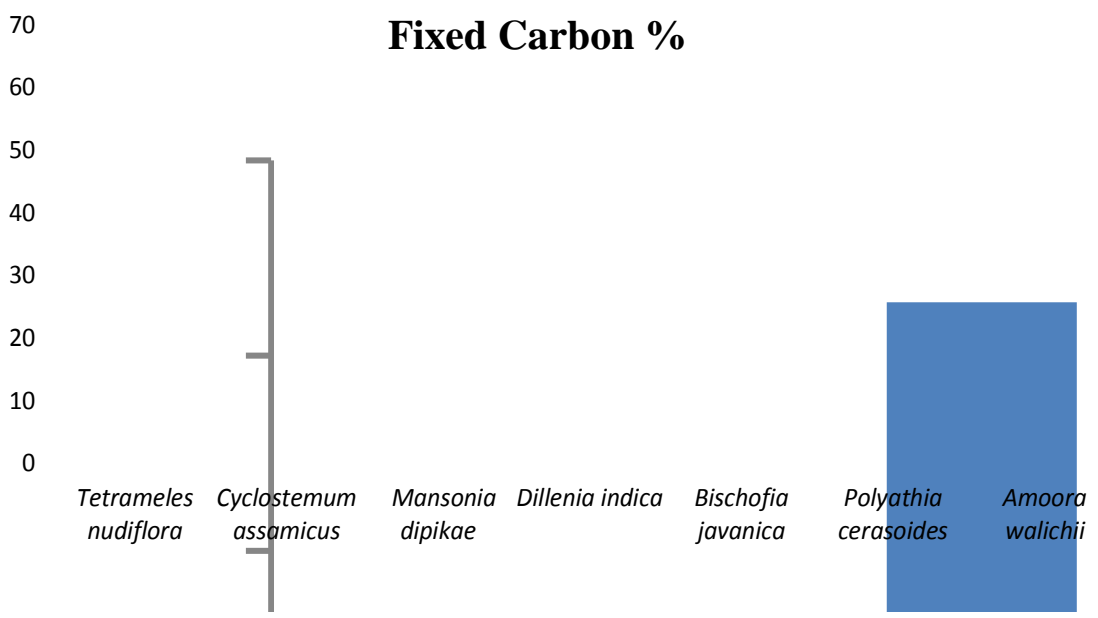

Fig.4 Carbon sequestration ( $\mathrm{tC}$ tree $\left.{ }^{-1}\right)$ of the selected tree species

$$
\begin{array}{r}
2.5 \\
3 \\
2.5 \\
2 \\
1.5 \\
1 \\
0.5 \\
0
\end{array}
$$

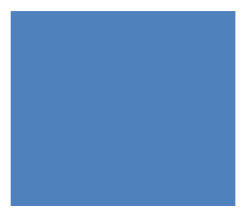

\section{Carbon Sequestration (t C/tree $\left.{ }^{-1}\right)$}

The estimation of the total carbon sequestered by the selected tree species are shown in Figure 3. It was recorded that the maximum total carbon sequestration $2.9774 \mathrm{tC}$ tree $^{-1}$ was found for Bischofia javanica followed by Tetrameles nudiflora $2.5442 \mathrm{tC}$ tree $^{-1}$. The minimum carbon sequestration was for Mansonia with $0.6688 \mathrm{tC}$ tree $^{-1}$.

Findings of above study concludes that the maximum total biomass was found for
Bischofia javanica with 7.570 tons sequestering 2.9774 tons of carbon followed by Tetrameles nudiflora 6.509 tons sequestering 2.5442 tons of carbon. The species Mansonia dipikae had the lowest carbon sequestration potential i.e. 0.6688 tons. Cyclostemum assamicus had the maximum fixed carbon of $62.7 \%$ followed by Amoorawalichii 59.3\%. Tetrameles nudiflora had the minimum fixed carbon of $38.4 \%$. The research can be useful for estimating carbon sequestration potential of the tree species found in Intanki National park, Nagaland for assessing the contribution in carbon sequestration by the 
tree species as well conservation aspects of above mentioned species for higher carbon stock.

\section{References}

Chhabra, A. and Dadhwal V. K. (2004) Assessment of major pool of fluxes of carbon in Indian forests.

Hu H., Y. Liu, and J. Yan (2007). Estimation of the carbon storage of forest vegetation and carbon emission from forest fires in Heilongjiang Province, China. Journal of Forestry Research.

Jana, B. K., S. Biswas, M. Majumder, P. Roy and A. Mazumdar (2009). Carbon sequestration rate and above ground biomass carbon potential of four young species. Ecology and Natural Environment.

Joshi Meenakshi, Preet Pal Singh (2003) Carbon sequestration by rehabilitating degraded forests in India.

Jussi Laurila (2013). Moisture content, weight loss and potential of energy wood in South and central Ostrobothnia regions in Western Finland. Dissertations Forestales.

Mani, S., N Parthasarathy (2007). Above ground biomass estimation in ten tropical dry evergreen forest sites of peninsular India. Biomass and Bioenergy.

Murali, K. S., D.M. Bhat, N. H. Ravindranath (2005). Biomass estimation equation for tropical deciduous and evergreen forests. International Journal of Agricultural Resources, Governance and Ecology.

Nishith Dharaiya and Jagruti Jagiwala (2013) Estimating carbon sequestration in forest vegetation through several scientific methods: a review to find competent method for Indian forest national monthly referred journal of research in science \& technology.

Onkar Salunkhe, P. K. Khare, T. R. Sahu and Sarnam Singh (2016) Estimation of tree biomass reserves in tropical deciduous forests of Central India by nondestructive approach. Tropical Ecology.

Pandya, Ishan Y. (2012) Estimation of carbon storage in heritage tree species of purnawil

Ravindranath N. H., Somashekhar R.S. and Cadgil M. 1997. Carbon flows in Indian forests. Dlife sanctuary of Dangs district of vibrant Gujarat. Indian Journal science.

Sah, J.P., et al., (2004). Estimating aboveground biomass of broadleaved woody plants in the understory of Florida Keys pine forests. Forest Ecology and Management.

Santantonio D, Hermann R K, Overton WS (1977). Root biomass studies in forest ecosystems.

Vashum, K. T. and S. Jayakumar. 2012. Methods to estimate above ground biomass and carbon stock in natural forest - a review. Journal of Ecosystem and Ecography.

Vendrapati Srinivasa Rao and Boyina Ravi Prasad Rao 2015 Carbon sequestration potential of tropical deciduous forests of Nallamalais, India. Biodiversity Conservation Division, Department of Botany, Sri Krishnadevaraya University, Anantapur, Andhra Pradesh, India.

Zhou, X., and M. A. Hemstrom (2009) Estimating Aboveground Tree Biomass on Forest Land in the Pacific Northwest: A Comparison of Approaches.

\section{How to cite this article:}

Anguno Tase, Amit Larkin and Hemant Kumar. 2018. Estimation of Carbon Sequestration of Selected Tree Species in Intanki National Park, Nagaland, India. Int.J.Curr.Microbiol.App.Sci. 7(09): 1488-1493. doi: https://doi.org/10.20546/ijcmas.2018.709.178 